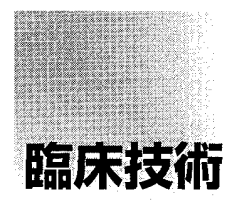

脂肪抑制，MTC併用2D-TOFによる下肢MR venographyの 有用性と各種加温方法の検討

\author{
東田満治・山崎＼cjkstart勝 ·佐原朋広・本塚勝康 \\ 大阪市立大学医学部附属病院中央放射線部
}

\section{はじめに}

下肢のmagnetic resonance angiography (MRA)におい ては, Gd造影風の $\mathrm{T}$ 短縮効果と三次元 $(3 \mathrm{D})$ 高速撮像 を併用した方法が確立しているがー3)，下肢MR venography (MRV)では種々の方法が試みられている4 9). そのなかで, 二次元time of flight (2D TOF) 法が, 比 較的短時間で選択的に静脈像を得ることができるとい
う理由から多く用いられている6 -9). しかし，2D TOF 法は，極端に遅い血流を信号としてとらえ難いこと や7)，血管以外の組織の高信号化に伴うコントラスト の低下10)といった問題がある.

こういった問題点に対処するために，血管以外の信 号抑制を目的として脂肪抑制とmagnetization transfer contrast (MTC) ${ }^{11)}$ を附加した2D TOF法を用いて，下肢

\title{
Usefulness of Lower Extremity MR Venography in 2D TOF Sequence with Fat Suppression Techniques and MTC, and Study of Different Warming Procedures
}

\section{MITSUJI HIGASHIDA, MASARU YAMAZAKI, TOMOHIRO SAHARA, and MASAYASU MOTOZUKA}

\author{
Department of Radiology, Osaka City University Hospital \\ Received May 16, 2000; Revision accepted Oct. 24, 2000; Code No. 261

\section{Summary}

We evaluated the effect of fat suppression techniques (fatsat) and magnetization transfer contrast (MTC) for MR venography (MRV) using the 2D TOF sequence in the lower extremities. In addition, the improvement of vessel conspicuity resulting from three different warming procedures was evaluated. Three combinations of fatsat and MTC were performed. Both the signal intensity ratio (SIR) and contrast-to-noise ratio (CNR) were measured at ROIs of vein, fat, and muscle in knee. The vessel conspicuity of MIP was evaluated by three radiologists. The experimental results indicated that MTC pulses did not affect fatsat. The combination techniques of fatsat and MTC improved SIR $(\fallingdotseq 13 \%)$ and CNR $(\fallingdotseq 5 \%)$ of the vein compared with techniques using fatsat only. The continuous warming procedure was better than temporary warming in terms of vessel conspicuity. We conclude that the combined techniques of fatsat and MTC with the continuous warming procedure were clearly useful for MRV using the 2D TOF sequence in the lower extremities.

Key words: Magnetic resonance venography (MRV), Two-dimensional time of flight (2D TOF), Magnetization transfer contrast (MTC), Fat suppression 
の加温による血流の改善12)を行った下肢MRVを施行 した．また，加温の方法について3種類の異なった加 温方法を考案して比較を行った。

本論文では，2D TOF法に脂肪抑制とMTCを附加し た場合の血管コントラストに㧈ける基礎的検討と，下 肢加温による静脈血管の描出能の評価を行い，その有 用性を報告する。

\section{1. 方 法}

\section{1-1 撮像方法}

使用装置は，シーメンス旭メディテック株式会社製 Vision 1.5Tである。撮像条件は, Table 1に示したと おりで，躯幹用コイルを用い，足関節部から上方 $80 \mathrm{~cm}$ について撮像を行った。撮像時間は約30分で, 頭-足方向のflow (動脈) 信号は，スライスと同期して 移動する presaturation pulseにより抑制した。

\section{1-2 脂肪抑制，MTCによるコントラスト特性}

脂肪抑制, MTC附加による静脈血管と他の組織の コントラスト特性をみるために，脂肪抑制，MTCの 有無による静脈血管と脂肪 (血管/脂肪)，静脈血管と 筋肉 (血管/筋肉)について信号強度比と contrast to noise ratio $(\mathrm{CNR})^{13)}$ を測定した。測定は，Table 1の条件に脂 肪抑制， MTC加えない場合を $\mathrm{F}-\& \mathrm{M}-$ ，脂肪抑制だけ を加えた場合を $\mathrm{F}+\& \mathrm{M}-$ ，脂肪抑制とMTCを加えた場 合を $\mathrm{F}+\& \mathrm{M}+$ とした 3 カテゴリについて行った．検討 の対象としたのは，健常ボランティア 8 名 (24-40歳 ; 平均30.8歳)の16肢の膝部で, その結果はpaired $\mathrm{t}$ 検定 を用いて有意差検定を行った。

なお, 脂肪抑制法は, 共鳴周波数の差を利用して脂 肪を選択的にプロトン飽和状態にするchemical shift saturation(CHESS) 法 ${ }^{14)}$ で, MTC法は, off resonance MTC法11である。 今回使用したMTCのoff resonance pulseは, 長さ7.68msの single cycle sinc pulseで水の周 波数から $1.5 \mathrm{kHz}$ 高い周波数に印加している.

\section{1-3 加温方法}

加温方法は，異なった 3 方法を行い，各々をWarm A，B，Cとした。また，加温しない場合をPlainとし てTable 1に示した条件を用いて撮像を行った。

Warm Aは，検查前に約 $45^{\circ} \mathrm{C}$ の温湯に 5 分間足を浸 した後，直ちに撮像を行った。Warm Bは市販の温湿 布を両下肢に数枚ずつ貼付し，貼付30分後より撮像を 開始した。Warm Cは下腿をやや熱い蒸しタオルで覆 い, 下肢周辺に湯枕を数個配置して加温開始直後から 撮像を行い, 検査中も持続的に湯峵で加温した。
Table 1 Scan parameters for MR venography in the lower extremities.

\begin{tabular}{ll}
\hline \hline Pulse sequence & 2D FLASH \\
Repetition time & $50 \mathrm{~ms}$ \\
Echo time & $9 \mathrm{~ms}$ \\
Flip angle & $65^{\circ}$ \\
Slice thickness & $4.0 \mathrm{~mm}$ \\
Field of view & $340-370 \mathrm{~m}$ \\
Rect.FOV & $4 / 8-5 / 8$ \\
Matrix (frequency $\times$ phase) & $256 \times 192$ \\
Fat suppression & CHESS \\
MTC & off resonance MTC \\
\hline
\end{tabular}

\section{1-4 加温方法の評価}

加温方法を評価するために以下に示す二つの方法を 用いた。

（1）Plain とWarm A，B，Cについて静脈血管の描出能 の評洒を行った．方法は，ボランティア 8 名の下 腿, 大腿部のcoronalのmaximum intensity projection (MIP) 像による視覚評価を行った。視覚評価 は，同一ボランティアについてウィンド幅，ウィ ンドレベルを一定としたフィルムによる読影で行 い, 各ボランティアのPlain とWarm A, B, Cの画 像において, 静脈血管を描出している本数, コン トラスト，走行について，1４位の順位付けを行 い，各順位に $4 \sim 1$ の点数を付けて総合点で評価し た。観察は，放射線技師 5 名で行い，その結果を Wilcoxon検定を用いて有意差検定を行った。

（2）下腿部16肢について，下腿深部静脈を構成する 3 本の静脈 (前脛骨静脈, 後脛骨静脈, 腓骨静脈) が，Warm A，B，Cで描出できた百分率を描出率 として求めた。観察は, 放射線科医師 2 名が行 い, 下腿のcoronal MIP像で, 各深部静脈の分枝 から下腿部中央附近まで連続して同定できた場合 を描出可能とした9).

\section{2. 結 果}

\section{2-1 脂肪抑制，MTCによるコントラスト特性}

脂肪抑制, MTCの有無による血管/脂肪の信号強度 比をFig. 1にCNRをFig. 2に示す．各グラフともに，F\&M-を1.0とした相対值で表している.

$\mathrm{F}-\& \mathrm{M}-$ 一比較すると，脂肪抑制を加えているF+＆ $\mathrm{M}-$ と $\mathrm{F}+\& \mathrm{M}+$ は，信号強度比で約6.8倍，CNRで約1.6 倍と大幅に向上した $(\mathrm{p}<0.001)$. また, MTCの有無に よる脂肪抑制効果に有意差は認められなかった。

Fig. 1，2 と同様に，血管/筋肉について求めた信号 強度比，CNRをFig. 3，4にそれぞれ示す. F- \& M- 


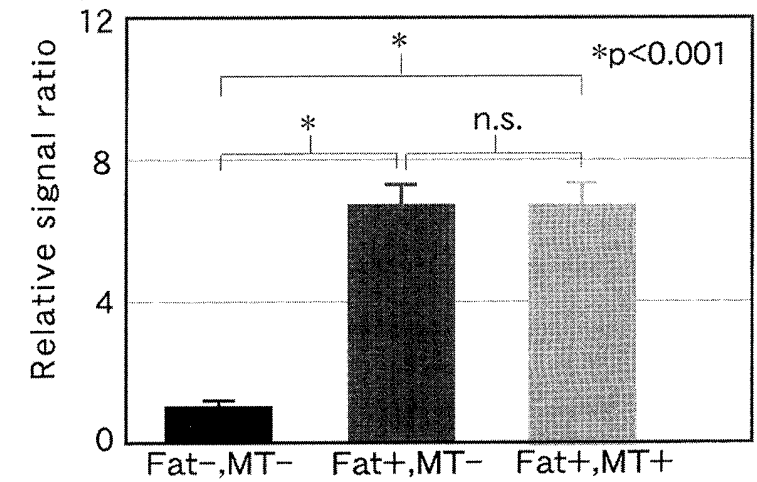

Fig. 1 Relative signal intensity ratio of the vein to the fatty region with three fat suppression techniques and the MTC. (n.s.=not significant)

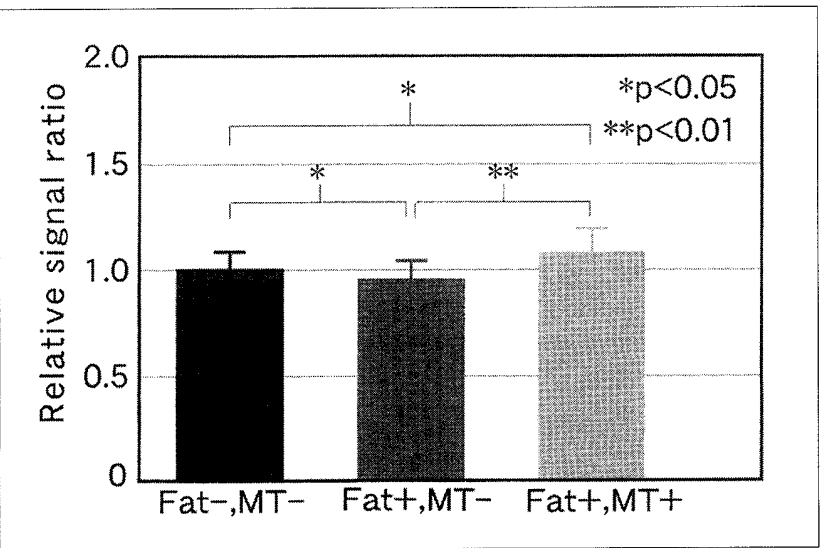

Fig. 3 Relative signal intensity ratio of the vein to the muscular region with three fat suppression techniques and the MTC.

と比較した場合，脂肪抑制だけを加えた $\mathrm{F}+\& \mathrm{M}-$ は， 信号強度比で約 $6 \%$ ，CNRで約 $15 \%$ の低下が認められ た。また，脂肪抑制にMTCを加えた $\mathrm{F}+\& \mathrm{M}+$ は， F+\&M-よりも信号強度比は約 $13 \%, \mathrm{CNR}$ は約 $5 \%$ の 向上が認められた。

\section{2-2＼cjkstart加温による効果}

Fig. 5に下腿部の，Fig. 6に大腿部の加温による血管 描出能の評価結果を示す。 Warm A，B，CともにPlain より血管描出能は向上し，すべての加温方法について 効果が認められた。加温法を比較した場合, 下腿部で はWarm C>A>B の順番となった。大腿部ではWarm C が最も加温効果が大きく, Warm A, B間で有意差は 認めなかった。

Table 2に下腿媣部静脈の描出率を示す．各静脈とも Fig. 5の結果と同様に, Warm $\mathrm{C}>\mathrm{A}>\mathrm{B}$ の順番で描出率 が高かった，静脈別では，後脛骨静脈が最も描出率が

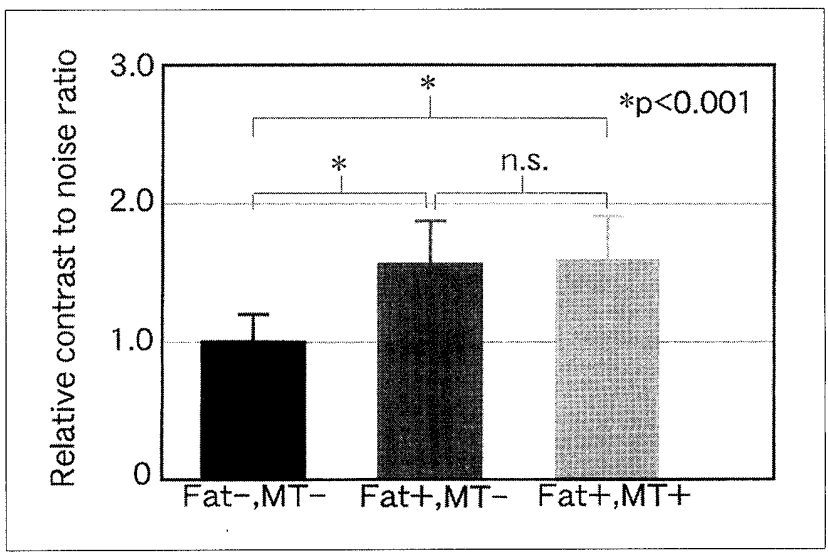

Fig. 2 Relative contrast-to-noise ratio of the vein to the fatty region with three fat suppression techniques and the MTC. (n.s.=not significant)

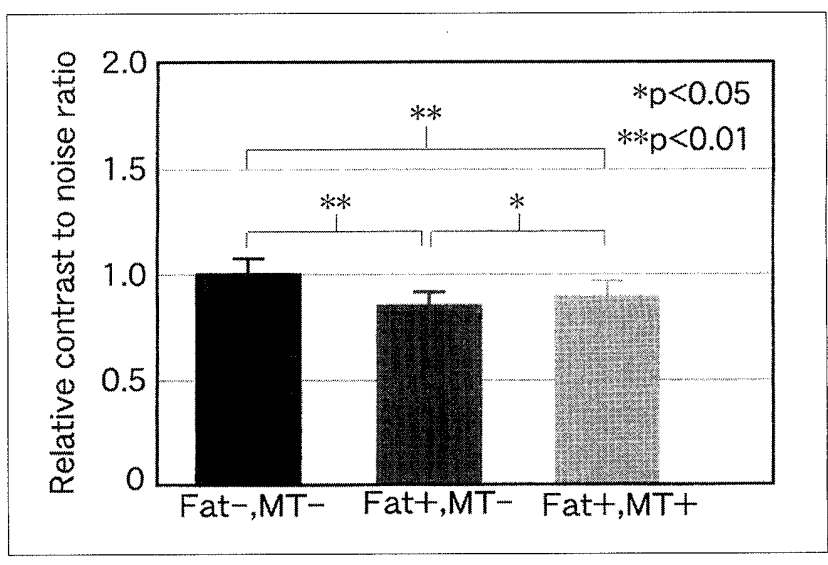

Fig. 4 Relative contrast-to-noise ratio of the vein to the muscular region with three fat suppression techniques and the MTC.

高く, 前脛骨静脈は低い描出率となった。

Fig. 7に同一ボランティアによるPlain と各加温法に よるMIP画像を示す．Plainと各加温法によって，下腿 部では明らかに静脈の描出能に差が生じている．各加 温法のなかでWarm Cだけが，下腿深部を構成する 3 本の静脈のすべてと，その分枝を足関節付近まで描出 することが可能である。また，大腿部に㧍いても， Warm Cが大腿染部静脈の連続性に優れ，分枝静脈に ついても描出能の向上が認められる。

\section{3. 考 察}

下肢MRVでは，Gd造影剂を肘静脈から注入して3D 高速撮像法で血管像を得る手法を用いた場合は，動脈 と静脈の重なりが問題となる7,8). また, 足背静脈か ら造影剤を注入する方法では，煩雑な手技と高侵襲性 から，血管造影検査に対する優位性が低くなる ${ }^{8)}$. 以 上のことから，2D TOF法は有用であると考えられる 


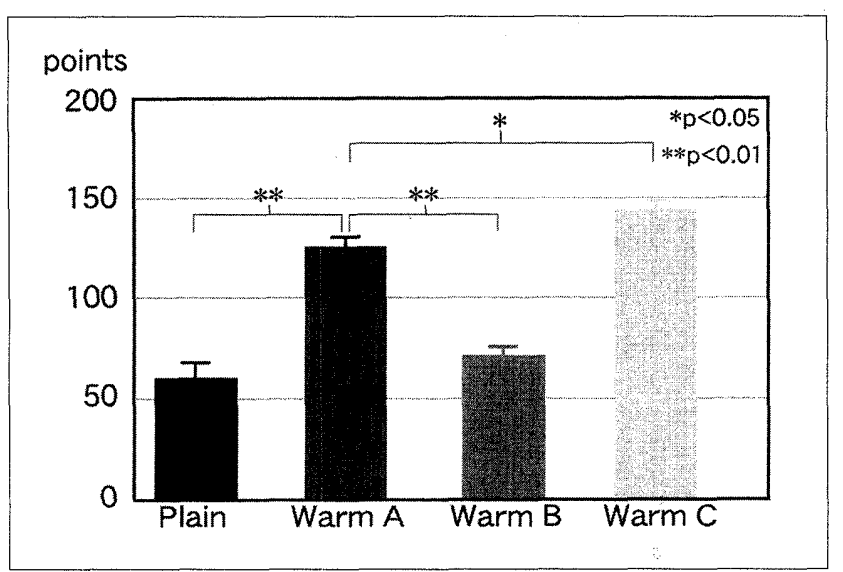

Fig. 5 Vessel conspicuity in the leg with different warming procedures.

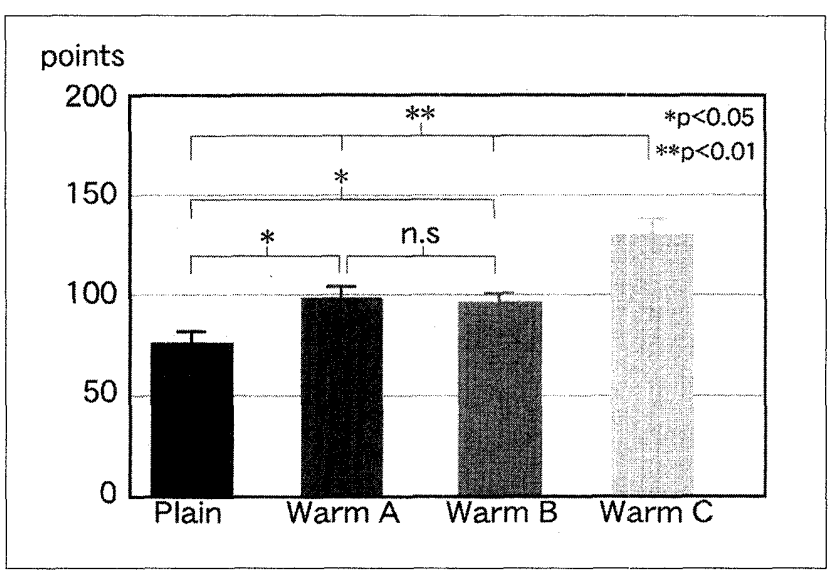

Fig. 6 Vessel conspicuity in the thigh with different warming procedures.

(n.s.=not significant)

Table 2 Detectability of three calf deep veins under different warming procedures.

\begin{tabular}{cccc}
\hline & Warm A (\%) & Warm B (\%) & Warm C (\%) \\
\hline Anterior tibial vein & 43.8 & 18.8 & 75.0 \\
Posterior tibial vein & 68.8 & 50.0 & 87.5 \\
Fibular vein & 62.5 & 43.8 & 81.3 \\
\hline
\end{tabular}
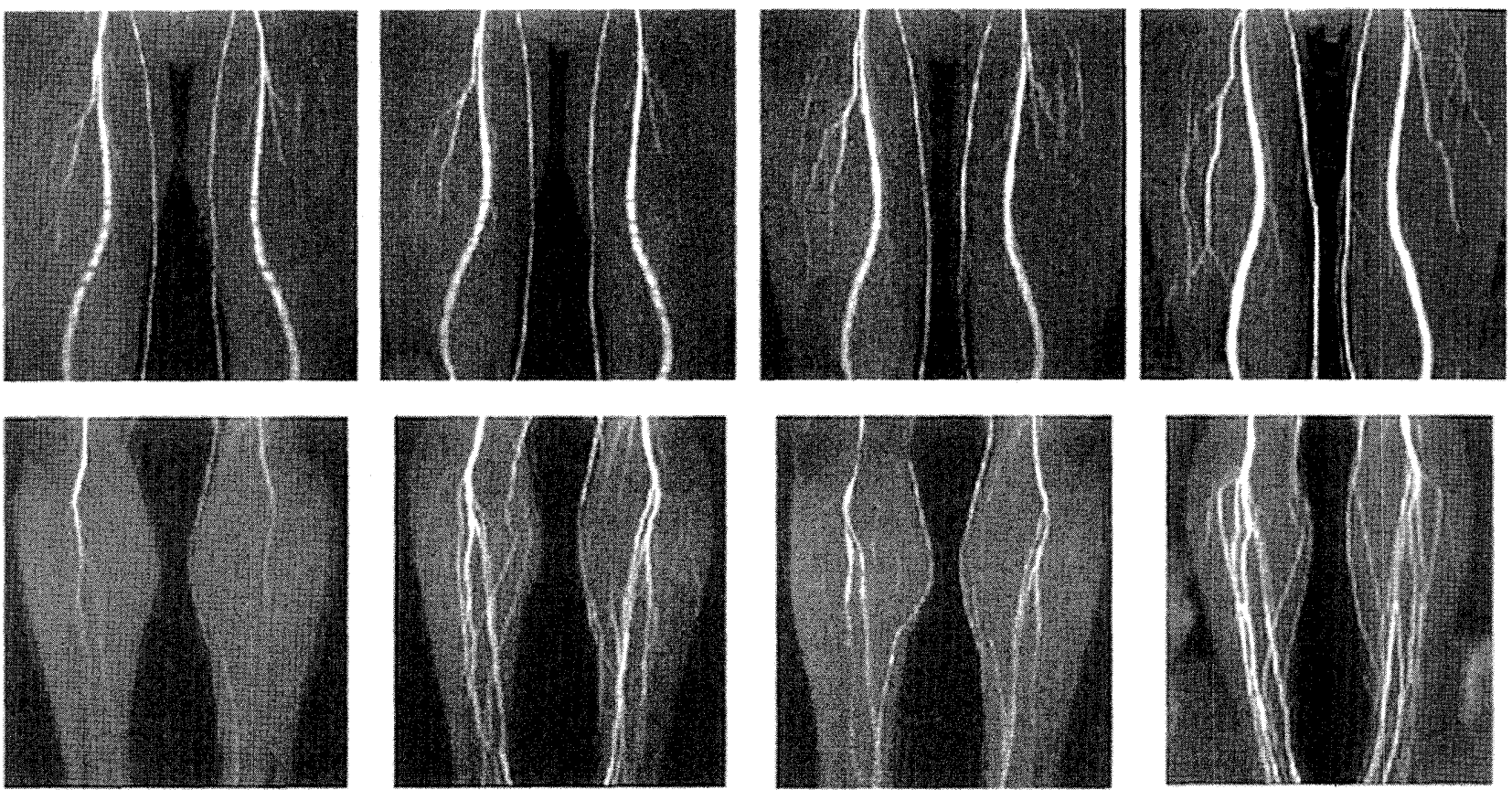

Fig. 7 Volunteer's MRV images (thigh and leg) with different warming procedures. (a) Plain, (b) Warm A, (c) Warm B, (d) Warm C

$a|b| c|c| c$

が，造影法のようにsubtaction処理ができないため， 血管以外の信号の抑制が重要となる. 解剖学的に，下 肢は内部を筋肉組織で, 周囲を脂肪組織で覆われてい
るので，本手法では，それらの信号を低下させること で，下肢静脈の描出能を改善させることを目的とし た。本手法の脂肪抑制は，静脈と脂肪のコントラスト 
の大幅な改善を認めたが，静脈と筋肉の信号強度比， CNRの低下をもたらした。しかし，脂肪抑制にMTC を附加すると脂肪抑制効果に変化がなく，静脈と筋肉 のコントラストを改善した。これより，脂肪抑制と MTCを併用することは，静脈と筋肉のコントラスト を損うことなく，大きな脂肪抑制効果が得られ，下肢 静脈のMRVに有効な撮像パラメータであると考えら れた。

また, CHESS法, off resonance MTC法の欠点とし て, repetition time (TR)の延長によるinflow効果の低 下と撮像時間の延長が挙げられるが，本法では，両方 を併用しても，TR 50msとMRAにおける適切なTR領 域10〉で設定が可能であり，問題とならなかった。

下肢静脈の血流改善の方法としてエタノール負 荷, 運動負荷, 駆血, 加温などの負荷が試みられて いる8,9).これらは，すべて血管の拡張を目的とする が，そのなかで多くの患者に対応が可能で，簡易的で あるという点で加温法が有効である．加温をしない Plainは，下腿の深部静脈をほとんど描出しなかった が7, 9)，各種加温法により有意に静脈の描出能向上を 認めた．加温法の比較では，持続的に目的部位を加温 するW arm Cが大きく，下腿深部静脈において描出困 難な前脛骨静脈 ${ }^{9)}$ も，75\%と高い描出率を示した。ま た，大腿部においても，加温効果は同等であった。 Warm Aは下腿部で，Warm Cに次いで效果が大きか ったが，撮像の後半にあたる大腿部では効果が小さ く，時間経過による加温効果の低下が認められた。 し
たがって，加温效果を最大限に得るには撮像時間中も 持続的に加温する必要があると考えられた。

Warm Bは，温湿布を貼付するだけの簡易的な方法 であるが, 加温法のなかで最も効果は小さかった。 温 湿布は貼付時間を長くするこにより効果を大きくでき る可能性があるが，実際の検查を考慮すると貼付30分 後の撮像は適当であると思われ，貼付時間による検討 は行わなかった。また，問題点として皮膚疾患やアレ ルギ一患者に不適であることや，温湿布費用の負担が あった。さらに，温湿布の一部に鉄分を含んだもが あり，使用の際には，事前の実験が必要である。

以上より, 加温方法は, 湯枕で持続加温するWarm Cが最も効果が大きかった。

\section{4. 結 語}

2D TOF法下肢MRVの描出能改善を目的にMTC, 脂 肪抑制，加温について検討した。結果として， MTC, 脂肪抑制により静脈と筋肉のコントラストを 損うことなく，静脈と脂肪のコントラストを向上でき た。各種加温により有意に血管描出能のは向上した が，湯枕で検査中も持続加温する方法が最も効果が大 きかった。

\section{謝 辞}

稿を終えるにあたり，本研究にご助言をいただきま した当院放射線科西田典史先生と，実験にご協力をい ただきまた技師諸见に深く感謝いたします。

\section{参考文献}

1) Adamis MK, LI W, WielopolskiPA, et al.: Dynamic contrastenhanced subtraction MR angiography of the lower extremities: Initial evaluation with a multisection two dimensional time-of-flight sequence. Radiology, 196, 689-695, (1995).

2) 天沼 誠, 田村綾子, 渡部恒也, 他：Gd-DTPA持続静注を 用いた骨盤，下肢動脈の 3 次元MR angiography. 日磁医 誌, 16(1)，13-21，(1996).

3) 東田満治, 山崎 勝, 花岡信子, 他 : 体躯用CP型phased array coilを応用したスライドテーブル式下肢造影3D MR angiography. 日放技学誌, 55(12)，1226-1231，(1999).

4) 橋本博美, 中塚春樹, 椿本光男, 他 : 2 次元位相コントラ スト法による下肢静脈のMRアンギオグラフィー。 日磁医 誌, 14(1)，11-19，(1994).

5）大川伸一，平松京一，森 達彦，他：3D-Fast STIRによる 下肢のvenography。 日本医放会誌，55(11)，774-775， (1995).

6) Lanzer P, Gross GM, Keller FS, et al.: Sequential 2D inflow venography: Initial clinical observations. Magn Reson Med, 19, 470-476,(1991).

7）田島なつき, 保坂純郎, 伊藤公一郎, 他：下肢静脈瘤の
MRA. 日磁医誌, 15 (6)，203-210，(1995).

8) 吉儀 淳, 土江洋二, 黑田 覚, 他: 下腿深部静脈MR venography－各種撮像法の検討一。日磁医誌, 19(S), 202, (1999).

9) 永吉健介, 周田宗正, 門前芳夫, 他: 非造影2D-TOF MR venographyによる下腿媣部静脈描出の向上に関する試み一 駆血および加温の有用性一，日本医放会誌，57(11)，647652, (1997).

10) Patrick $T$, Matt $B$, Orest $B$, et al.: Signa Advantage Applications Guide Vol.3. General Electric Company Publication, Milwaukee, Wisconsin, (1990).

11) 佐藤俊彦, 森谷浩人：交差緩和の臨床応用とその問題点. 日獨医報，42(1)，19-30，(1997).

12) 水口和夫，工藤弘明，奥山和夫，他：温湿布下IV DSAによ る四肢末梢部動脈造影。臨床放射線，31，161-163， (1986).

13）日本放射線技術学会 編：臨床放射線技術実験ハンドブッ ク (上). pp.531-535, 通商锉業研究者, 東京, (1996).

14) Haase A and Frahm J: $1 \mathrm{H}$ NMR chemical shift selective (CHESS) imaging. Phys Med Biol, 30 (4), 341-344,(1985). 
Fig. 1 脂肪抑制とMTC有無の 3 カテゴリの静脈/脂肪の相対信号強度比 (n.s.は有意差なし).

Fig. 2 脂肪抑制とMTC有無の3カテゴリの静脈/脂肪のCNR (n.s.は有意差なし).

Fig. 3 脂肪抑制とMTC有無の3カテゴリの静脈/筋肉の相対信号強度比.

Fig. 4 脂肪抑制とMTC有無の3カテゴリの静脈/筋肉のCNR.

Fig. 5 下腿部の各種加温法による血管描出能の評価.

Fig. 6 大腿部の各種加温法による血管描出能の評価(n.s.は有意差なし).

Fig. 7 各種加温法によるMIP画像(下腿部, 大腿部).

(a) Plain, (b) Warm A, (c) Warm B, (d) Warm C

Table 1 下肢MR venographyの撮像条件.

Table 2 各種加温法による下腿の 3 本の深部静脈の描出率. 